\title{
AGRICULTURA FAMILIAR, SISTEMAS AGROALIMENTARES LOCALIZADOS - SIALS E AS DINÂMICAS DE DESENVOLVIMENTO DOS TERRITÓRIOS RURAIS
}

\author{
FAMILY AGRICULTURE, AGRIFOOD SYSTEMS LOCATED \\ (SIALS) AND THE DEVELOPMENT DYNAMICS OF RURAL \\ TERRITORIES
}

Jorge Luiz Amaral de Moraes

Universidade de Santa Cruz do Sul e Faculdades Integradas de Taquara - Santa Cruz do Sul - RS - Brasil

\begin{abstract}
Resumo: Este artigo teve como objetivo principal buscar evidências teóricas de que os Sistemas Agroalimentares Localizados - SIALs podem ser um importante instrumento de viabilização socioeconômica da agricultura familiar e de desenvolvimento rural. As ferramentas teóricometodológicas utilizadas são os conceitos e proposições referentes à formação de Sistemas Agroalimentares Localizados - SIALs e a abordagem territorial do desenvolvimento rural. Buscou-se argumentos que pudessem explicitar as eventuais relações entre a agricultura familiar, os Sistemas Produtivos Localizados - SPLs e as dinâmicas de desenvolvimento dos territórios rurais. O contexto dessas relações é a intensificação do debate sobre a gestão territorial do desenvolvimento e as mudanças nas dinâmicas de produção agroalimentar, no reconhecimento da importância da agricultura familiar e das aglomerações produtivas locais para o desenvolvimento rural. Os resultados sugerem que os SIALs podem se tornar um importante mecanismo de articulação da agricultura familiar com a dinâmica de desenvolvimento dos territórios rurais e com o processo de reestruturação do sistema produtivo global. A busca por melhor qualidade de vida e infraestrutura rural, maior diversificação das atividades agroalimentares, agroindustriais e turísticas, que utilizem os recursos ambientais de forma sustentável e que gerem renda e emprego para as famílias rurais, são fatores que podem contribuir para uma desaceleração ou reversão dos fluxos migratórios ruralurbano.
\end{abstract}

Palavras-chave: Sistemas Agroalimentares Localizados. Desenvolvimento rural. Agricultura familiar. Territórios rurais.

Abstract: This article dad as aimed to seek theoretical evidence that Agrifood Systems Located (SIALs) can be an important instrument of socio-economic viability of the family farming and rural development. The theoretical and methodological tools used are the concepts and propositions concerning the formation of Located Agrifood Systems (SIALs) and territorial approach to rural development. It sought to arguments that could explain the possible links between family farming, the SPLs and dynamics of development of rural areas. The context of these relations is intensifying the debate about territorial management of the development and changes in the agri-food production dynamics, in recognition of the importance of family farming and local productive agglomerations to rural development. The results suggest that the SIALs can become an important mechanism of articulation of family farming with the dynamics of development of rural territories and the global production system restructuring process. The search for better quality of life and rural infrastructure, greater diversification of agrifood, agribusiness and rural tourist activities, that use environmental resources sustainably and generate income and employment for rural families are factors that may contribute to a slowdown or reversal of rural-urban migration.

Keywords: Agrifood Systems Located. Rural development. Family farming. Rural territories. 


\section{Introdução}

Este artigo busca contribuir para o debate teórico em torno da relação entre a agricultura familiar, os sistemas agroalimentares locais e as dinâmicas de desenvolvimento rural. Poderá ser útil, também, como ponto de partida para análises mais aprofundadas dos impactos do processo de reestruturação do sistema produtivo global sobre as dinâmicas de desenvolvimento dos territórios rurais, assim como, para a elaboração e execução de políticas públicas e privadas direcionadas ao desenvolvimento regional.

Duas das mais importantes correntes teóricas de interpretação do capitalismo contemporâneo, os neo-schumpeterianos e os regulacionistas, cada um a seu modo, afirmam que se está vivenciando um momento de inflexão entre duas fases do capitalismo. Estamos iniciando um novo ciclo ou regime de acumulação capitalista, passando do fordismo para um pós-fordismo. Para os neoschumpeterianos, a alteração da matriz produtiva da sociedade contemporânea caracteriza uma mudança de paradigma produtivo e uma revolução tecnológica, início de um novo ciclo, um novo impulso para a acumulação capitalista, com novas e mais amplas oportunidades, que já se verifica em muitas cadeias produtivas.

A interpretação da escola regulacionista para o capitalismo é a de que este gera crises que requerem uma reestruturação produtiva e o estabelecimento de novos mecanismos de estabilidade (temporária) do sistema. Esta é obtida mediante a criação de regimes de acumulação, períodos históricos com condições favoráveis à reprodução do processo de acumulação de capital e à manutenção de níveis socioeconômicos capitalistas aceitáveis (BOYER, 1995). Assim, na década de 1970, teve início um processo de crise do regime de acumulação fordista, que se aprofundou a partir de 2008, quando as estruturas macroeconômicas que garantiam o crescimento econômico do pós-guerra não foram capazes de manter a expansão desse regime, que perdeu velocidade devido à falta de flexibilidade $e$ sustentabilidade das cadeias e sistemas produtivos.

Da mesma forma, o processo global de reestruturação da produção capitalista, iniciado no final do século passado, com a ascensão do capital transnacional, o uso de novos sistemas de transportes e comunicação e articulações globais da produção, passou a influenciar também a produção e o comércio agroalimentar. Esse processo desencadeou diversas linhas de abordagem nas análises da agricultura, dos sistemas produtivos agroalimentares e das dinâmicas de desenvolvimento rural.

$\mathrm{Na}$ década de 1980, como resultado de análises das dinâmicas de desenvolvimento rural na Europa, três importantes organizações internacionais publicaram relatórios apontando para o esgotamento do modelo tradicional de desenvolvimento rural. Os relatórios foram o da Comissão Mundial do Ambiente e do Desenvolvimento das Nações Unidas ("O Nosso Futuro Comum"), em 1987, o da Comissão Europeia ("O Futuro do Mundo Rural"), em 1988, e o da OCDE ("Formulation de la Politique Rurale. Nouvelles Tendances"), também em 1988. Esses relatórios demonstraram que a crise do mundo rural europeu não era somente setorial, mas, principalmente, uma consequência de suas dificuldades para se integrar ao modelo de desenvolvimento da sociedade contemporânea 
como um todo e ao processo de reestruturação produtiva capitalista que se iniciava.

Então, a Política Agrícola Comum - PAC passou a incorporar, de forma mais explícita, as preocupações com as políticas e medidas para o reordenamento territorial e para o desenvolvimento rural e, ao mesmo tempo, a elaborar uma doutrina teórica que servisse de base de apoio para essas políticas. Com isso, as políticas voltadas para o desenvolvimento rural na Europa tiveram mudanças significativas depois que as diferenças regionais e territoriais passaram a ser valorizadas e potencializadas.

Com isso, na Europa houve o reconhecimento de que a diversidade e as potencialidades regionais-locais poderiam ser elementos estratégicos para a competitividade local dentro das políticas de apoio ao desenvolvimento rural. As especificidades territoriais passaram a ser consideradas relevantes para a elaboração dessas políticas, que deixaram de adotar tipologias simplificadas e abriram espaços para a participação da população local na elaboração e implantação dessas políticas. Enfim, os atores sociais abandonaram a ideia de políticas exclusivamente setoriais (agrícolas) e passaram a incorporar em seus planos políticas territoriais que levassem mais em conta a complexidade estrutural dos espaços rurais-regionais. O programa LEADER da União Europeia tem sido o principal exemplo de operacionalização dessas políticas.

$\mathrm{Na}$ esteira desse processo histórico, ainda na década de 1990, alguns pesquisadores, utilizando diferentes perspectivas teóricas, passaram a dar mais ênfase aos fatores endógenos e às aglomerações produtivas nos processos de desenvolvimento territorial-local. Então surgiram novas interpretações analíticas relacionadas às aglomerações produtivas regionais-locais e às novas dinâmicas de desenvolvimento dos territórios. Em consequência, cresceu em torno dos estudos sobre o desenvolvimento rural uma corrente contemporânea de pensamento que vem enfatizando a dimensão territorial do desenvolvimento. Esta não estuda somente as vantagens ou obstáculos geográficos de localização, mas também a formação de aglomerados produtivos e redes de cooperação que facilitem as ações cooperativas e de reciprocidade, capazes de enriquecer o tecido social local (ABRAMOVAY, 2000).

No Brasil, a crise fiscal do Estado e os processos de descentralização, nesse mesmo período impulsionaram uma crescente valorização do papel dos governos locais como agentes de renovação das políticas públicas, tanto para o meio urbano como para o rural. Essa tendência foi reforçada pelo processo de reconfiguração dos padrões de consumo e produção agroalimentar e pela internacionalização dos fluxos de capital. Com a modernização da agricultura brasileira, essas mudanças passaram a se expressar no grau de desenvolvimento tecnológico, associado ao aumento do desemprego estrutural e do êxodo rural. Além disso, ainda existe um expressivo contingente de agricultores familiares com rendas insuficientes para a sustentação socioeconômica familiar, pressionando os governos locais a buscarem alternativas para enfrentar o problema.

Conforme dados do último Censo Agropecuário do Instituto Brasileiro de Geografia e Estatística - IBGE (2006), a agricultura familiar era responsável por $70 \%$ da produção de alimentos no Brasil, representando $10 \%$ do produto interno bruto - PIB nacional e $75 \%$ da mão de obra trabalhadora no campo. No entanto, ainda há um importante segmento da agricultura familiar brasileira que não 
consegue se sustentar economicamente devido aos mecanismos de comercialização da produção e dos insumos. Além disso, muitas vezes a vinculação ao mercado ocorre por meio de intermediários ou comerciantes regionais-locais, o que reduz as margens de escolha na comercialização e as possibilidades de acesso ao crédito e à informação.

Tendo em vista esse cenário, este estudo tem como objetivo principal buscar evidências teóricas de que os SIALs podem ser um importante instrumento de viabilização socioeconômica da agricultura familiar e de desenvolvimento rural. Isto seria possível por meio da "aproximação" da produção familiar com os principais mercados, locais, institucionais e externos de produtos agroalimentares, ambientais e turísticos, potenciais geradores de mais renda e postos de trabalho.

As ferramentas teórico-metodológicas utilizadas para se atingir esse objetivo são os conceitos e proposições referentes à formação de aglomerados produtivos locais, particularmente os SIALs, e ao desenvolvimento territorial-rural. Para demonstrar o potencial das aglomerações produtivas locais como mecanismo de articulação da agricultura familiar com os grandes mercados consumidores de alimentos, tanto internos como externos, e com a reestruturação produtiva mundial foram utilizados os resultados empíricos de dois estudos realizados no Rio Grande do Sul. Estes foram feitos entre 2013 e 2015, na região Vale do Caí e na região de abrangência da Cooperativa Languiru, com sede em Teutônia-RS, utilizando-se dados secundários sobre produção agropecuária.

Por isso, buscaram-se argumentos que pudessem explicitar as eventuais relações entre a agricultura familiar, os SIALs e as dinâmicas de desenvolvimento dos territórios rurais. O contexto em que estão inseridas essas relações é a intensificação do debate sobre a possibilidade de gestão territorial (regional-local) do desenvolvimento, iniciado no final do século passado, e as recentes mudanças nas dinâmicas espaciais da produção agroalimentar, no reconhecimento da importância da agricultura familiar e das aglomerações produtivas locais para o desenvolvimento dos territórios rurais.

Tendo como horizonte a possibilidade de os SIALs, um tipo específico de aglomeração produtiva, passarem a configurar como um importante modelo de desenvolvimento rural, este estudo propõe uma conformação mínima para que os SIALs possam representar um novo ambiente socioeconômico, como mecanismo de desenvolvimento dos territórios rurais. Para isso, procurou-se identificar, na literatura disponível, os mecanismos que pudessem explicar a reprodução desses sistemas e as suas formas estruturais socioeconômicas e, também, destacar os principais fatores que articulam a agricultura familiar e os SIALs com as dinâmicas de desenvolvimento dos territórios rurais.

Este texto, além desta introdução e das considerações finais, apresenta mais três seções. A seguir, descreve-se uma síntese do debate sobre o papel da agricultura familiar no processo de reestruturação da produção capitalista no final do século passado. Na seguinte, apresenta-se a emergente abordagem territorial do desenvolvimento rural. $\mathrm{Na}$ quarta seção busca-se evidenciar o potencial dos SIALs como um mecanismo de articulação da agricultura familiar com as dinâmicas de desenvolvimento dos territórios rurais, incluindo-se informações empíricas referentes a dois territórios do Rio Grande do Sul, a região Vale do Caí e o território formado pelos municípios de abrangência da cooperativa Languiru, com sede no Município de Teutônia, na região Vale do Taquari. 


\section{A agricultura familiar e o processo de reestruturação da produção capitalista}

De acordo com Bonanno (1998), o processo de reestruturação produtiva do capitalismo, iniciado no final século passado, desencadeou diversas linhas de abordagem nas análises da agricultura e dos sistemas produtivos agroalimentares. Entre essas linhas de abordagem, uma das principais é a regulacionista, que salienta a necessidade de considerar uma perspectiva histórica mais longa dos sistemas agroalimentares, dando maior ênfase na evolução dos regimes de acumulação capitalista, períodos de estabilidade entre uma crise e outra. Assim, uma das estratégias de "saída" do fordismo seria a experimentação flexível do trabalho e uma nova configuração internacional da divisão do trabalho, com novos setores de acumulação, transferências de empresas para regiões mais periféricas. Nestas, os níveis salariais são mais baixos e há um crescente aumento do número de pequenas empresas, onde o processo de trabalho é mais flexível e os custos de produção são menores (BENKO, 2002).

Embora tenha obtido sucesso para explicar a crise global, a teoria da regulação passou por algumas dificuldades teóricas para tratar da agricultura e da produção de alimentos. Isto porque a "relação salarial", conceito-chave da abordagem teórica regulacionista, até hoje não faz muito sentido na agricultura, devido à grande predominância do trabalho de origem familiar na formação dos seus rendimentos, em que o agricultor familiar é, ao mesmo tempo, trabalhador e produtor-proprietário. Boyer (1995) afirma que as duas principais dificuldades dessa abordagem são: a articulação da aplicação setorial da teoria com a regulação global; e a aplicabilidade ou adaptação dos conceitos-chave da teoria da regulação em atividade (s) com características muito particulares, onde predominam o trabalho relativamente independente e as explorações familiares.

No entanto, Lacroix e Mollard (1995) afirmam que é perfeitamente possível analisar e inserir a agricultura no modo de regulação global quando se leva em conta a sua coerência econômica e institucional construída a partir da segunda metade do século XIX. Os principais elementos para justificar essa possibilidade seriam: as características da organização técnica e socioeconômica, comuns à maioria das unidades de produção; o fato de a agricultura se constituir em um espaço privilegiado de concorrência entre os produtores; e, a presença de dispositivos institucionais e sociais, historicamente construídos. Para incorporar a agricultura familiar na análise regulacionista, que é setorial, no sentido de verificar a contribuição dessa teoria para o estudo da agricultura familiar, Lacroix e Mollard (1995) sugerem que não sejam separados os conceitos de regime de acumulação e relação salarial, como normalmente se faz no esquema da regulação global.

Então a agricultura e a produção de alimentos passam a se inserir no fordismo e no desenvolvimento do capitalismo, oferecendo força de trabalho e alimentos baratos e absorvendo parte da produção urbano-industrial, como se verificou no processo de modernização da agricultura brasileira. A partir da metade dos anos 1980, a intervenção estatal se reduz e abre caminho para os capitais globais mais amplos.

Uma nova etapa da expansão capitalista da produção de alimentos, mais neo-fordista do que pós-fordista, também denominada de terceiro regime de alimentação, vem sendo construído sobre mercados diversificados e com uma 
orientação dada pelo consumo e pelas corporações varejistas, acentuando as desigualdades entre espaços locais e regionais de desenvolvimento, dominação e dependência (MARSDEN, 1997). Da mesma forma que este terceiro regime de alimentação ainda está muito longe de uma definição. A nova divisão internacional do trabalho também não está definida ainda. No entanto, é possível que a produção de grãos e de alimentos duráveis passe a ser feita predominantemente pelos países em desenvolvimento e os países desenvolvidos fiquem com o processamento e os serviços, dentro das cadeias produtivas, segmentos que agregam mais valor (GRAZIANO DA SILVA, 2000).

Marsden (1998), referindo-se à necessidade de se buscar uma análise comparativa internacional dos territórios rurais, afirma que, no atual contexto das relações entre o global e o local, essa necessidade cresce à medida que os espaços rurais se tornam também espaços de competição e de mercantilização. Ele diz que a questão analítica se constitui em como dar sentido ao espaço rural e compreender como ele vem se diferenciando ao longo do tempo.

As questões que surgem dessa nova realidade se referem aos estudos das causas e razões para que os espaços rurais sejam diferentes e os impactos sociais, econômicos e ambientais gerados pelo desenvolvimento contemporâneo. Segundo Marsden (1998), estas questões são prioritárias na agenda da nova sociologia rural e agrária, principalmente quando se refere aos estudos dos processos das cadeias de produção e consumo e da inserção das áreas rurais, dos territórios e de seus atores nessas cadeias e redes de conexão.

Para Bonanno (1998), a transição do fordismo para o pós-fordismo global também é discutida no contexto dos debates sobre as mudanças no sistema agroalimentar. Para ele, uma alternativa crítica importante aos pressupostos das teorias regulacionistas e ao fim do fordismo, proposta na segunda metade da década de 1990, é a de William H. Friedland.

Embora concordando que tenham se confirmado as tendências para a especialização e a globalização da produção, Friedland, apud Bonanno (1998), entende que essas tendências não são caracterizadas por um processo artesanal, citando como o exemplo o caso da produção de frutas e vegetais in natura na Holanda. Nesse país, a presença de pequenas unidades produtivas e a descentralização de um amplo sistema de integração vertical não representa o fim da produção em massa e a concomitante emergência de um sistema artesanal de produção. Isso, segundo ele, indica o desenvolvimento de um sistema de produção em massa bem mais sofisticado e que está ancorado nas pequenas unidades de produção "independentes" apenas informalmente. Essas pequenas unidades são controladas pelas grandes corporações transnacionais, que empregaram esquemas técnicos e legais para fragmentarem o poder de barganha das unidades de produção. Esse parece ser o caso da produção de tabaco no sul do Brasil.

Segundo Friedland, apud Bonanno (1998), a formação de nichos de mercado é o tópico principal para se entender a produção em massa individualizada, pois este fenômeno é a fragmentação de um mercado de massapadrão em uma variedade de mercados com produtos especializados. Isso responde à crise nos mercados homogêneos de massa, pois introduz um sortimento de produtos necessários para o atendimento das novas demandas dos consumidores globais. Na essência, apesar da aparente independência dos produtores, o processo de trabalho e os produtos mantêm seu caráter fordista e 
continuam totalmente controlados por aqueles setores que estão "acima" dos produtores. A teoria dos nichos de mercado permite a Friedland rejeitar as teses do fim do fordismo e a transição para o pós-fordismo.

Para Bonnano (1998), embora o argumento de Friedland seja consistente e faça a ligação efetiva entre a evolução das estratégias de produção com as estruturas de classe das sociedades capitalistas desenvolvidas, ele pode ser questionado pelo fato de estar muito focado na produção e de que suas críticas dizem respeito apenas ao segmento mais otimista da escola da regulação. Com as redes globais de alimentos, os processos de acumulação agrícola e de alimentos tornam-se mais diferentes uns dos outros, com o valor dos alimentos sendo cada vez mais construído nas etapas posteriores à produção agropecuária das redes alimentícias.

As consequências mais importantes para os produtores rurais familiares nos países em desenvolvimento como o Brasil são: a concentração cada vez maior da produção de commodities, que conseguem se inserir nas cadeias produtivas transnacionais; e, com o fato de a coordenação dessas cadeias estar agora a cargo das próprias transnacionais, acelera-se também o processo de verticalização da produção agroindustrial. Como exemplo, no Brasil, isso é o que se verifica na produção de soja, frango, tabaco, entre outras. Com isso seriam as próprias empresas transnacionais ou as grandes cooperativas nacionais que, diretamente ou por meio de mecanismos contratuais variados, passam a dominar também a órbita da produção agrícola stritu sensu (CAMPANHOLA E GRAZIANO DA SILVA, 2000).

\section{Desenvolvimento territorial-rural}

O desenvolvimento territorial tem como "combustível" principal o uso efetivo das capacidades, competências e habilidades dos atores locais e a sua identidade social e histórica com o território. Isto se verifica no gerenciamento dos fatores locais, atuais e potenciais, na incorporação de conhecimentos e na transformação de oportunidades externas em possibilidades internas, com o objetivo de resolver problemas ou atender necessidades locais, promover o dinamismo econômico e a melhoria da qualidade de vida da população. Ele pode ser considerado um novo paradigma de desenvolvimento, emergindo da organização de uma sociedade local em torno de uma estratégia de desenvolvimento do território. Em função dessas características, o conceito de desenvolvimento territorial tem sido utilizado como sinônimo de desenvolvimento local, endógeno ou regional.

Nas atuais teorias e políticas de desenvolvimento regional, a premissa tem sido a necessidade de pensar a região como um território ou um sistema local que sofre influência de variáveis internas (participação, ambiental, social, econômica e a cultural) e tem grande interação com os sistemas territoriais de maior escala ou globais. Sob o ponto de vista socioeconômico, as ações devem ter como objetivo a implantação e gestão de projetos dinamizadores da economia e dos recursos regionais-locais, que promovam a geração de renda e de oportunidades de trabalho e fortaleçam as ações e políticas estratégicas de integração competitiva no mercado global (MORAES, 2008). 
As ligações e as relações entre o global e o local dentro dos territórios são realizadas utilizando-se as articulações entre os referenciais teóricos do território, da abordagem territorial do desenvolvimento e das aglomerações produtivas locais-territoriais, que no caso dos territórios rurais são denominadas de SIALs.

\subsection{O Conceito de Território}

O conceito de territorialidade tem origem na complexidade de contextos históricos e sociais. De acordo com Sack (1980), a construção social da territorialidade só existe se houver interação entre os indivíduos. É o contexto social que estabelece o "conteúdo" humano para o território. Sem este conteúdo territorial, o mesmo fica restrito às suas dimensões espaciais, mediadas pela dimensão geográfica. Para o autor, a territorialidade é uma afirmação consciente do controle, mesmo que os atores envolvidos não estejam conscientes disso. As relações que dão forma à territorialidade são complexas porque envolvem a sociedade e as suas interações e, ainda, porque há conexões entre os conflitos e as condições sociais.

Becker (1986) define o território como sendo resultante da relação da sociedade com o espaço, quando neste se incorpora a sociedade com suas relações produtivas e econômicas. Para que exista um território, é necessário que a sociedade se aproprie do espaço físico, se ampliem e se utilizem as inovações tecnológicas e que exista um sentimento de pertencimento ou a identificação da sociedade com o seu território. A legitimação do território passa pelo discurso e pela negociação em relação à história, à política, à ciência, ao mercado e às relações sociais.

Para Boisier (2000), o território é um recorte da superfície terrestre que se apresenta como um conjunto de três características: um território "natural" (espaço), sem considerar a presença humana; um território "equipado", onde se verifica a presença humana através da instalação de fluxos e de atividades produtivas e extrativas; e o território "organizado", quando aparecem atividades humanas e fluxos mais complexos.

O uso do território pode ser um importante instrumento para estabelecer os limites das vantagens potenciais resultantes do desenvolvimento desse território, tanto físicos como simbólicos. A definição de território rural, ao superar a dicotomia rural-urbano, incorpora tanto as cidades com seu entorno como todas as suas áreas rurais e agrícolas. Além disso, no estudo das dinâmicas dos territórios rurais podem ser encontradas formas de aglomerações ou sistemas produtivos locais (ou localizados) com características agroalimentares, denominados de SIALs.

\subsection{Desenvolvimento dos Territórios Rurais}

$\mathrm{Na}$ década de 2000, começaram a surgir estudos baseados na abordagem territorial do desenvolvimento rural, na qual as perspectivas do local e do endógeno estão presentes. Nesse ponto, é referência obrigatória o texto de Schejtman \& Berdegué (2003), que descrevem, de forma sistemática, a evolução do enfoque territorial e os conceitos e critérios operativos da abordagem centrada no Desenvolvimento Territorial Rural - DTR. Os autores reforçam a ideia de que a 
produção pode se articular, de forma competitiva e sustentável, com a economia interna do território e com mercados externos dinâmicos.

No Brasil, novas perspectivas de estudo do desenvolvimento regional-rural vêm substituindo a visão tradicional baseada na dicotomia rural-urbana, que confundia o rural com o agrícola, por uma visão sobre o mundo rural baseada na possibilidade de os territórios rurais incluírem também as pequenas cidades do "interior". Assim, seriam possíveis novas alternativas de ocupação e renda e diversas outras formas de melhoria na qualidade de vida da sua população. Isso é de grande relevância para o estudo de regiões com muitos municípios pequenos e/ou com grande contingente de população rural.

No debate brasileiro dos últimos anos, verifica-se uma mudança de visão nas novas abordagens utilizadas para compreender o papel do "rural" no desenvolvimento regional do país. Essas novas abordagens de estudo do desenvolvimento territorial rural tendem a substituir a visão tradicional que relacionava o rural com atraso e como sinônimo de agrícola e, por outro lado, o urbano com moderno, industrial e com o setor de serviços.

Quando se utiliza o termo "dinâmica territorial rural", como sendo o ambiente onde é possível, ao mesmo tempo, a utilização das potencialidades próprias do território e o aproveitamento das oportunidades externas, de diversas formas, se constituem numa dinâmica socioeconômica local diferenciada de desenvolvimento rural, instrumentalizada e mediada através de suas aglomerações produtivas (CORREA,2004; SABOURIN,2002; SCHEJTMAN \& BERDEGUÉ,2003; SCHNEIDER,2003).

$\mathrm{Na}$ tentativa de estabelecer uma ponte hierárquica entre os significados de rural e local nos programas de desenvolvimento, Wanderley (2001) argumenta que os programas de desenvolvimento local, em vez de substituir o desenvolvimento rural, incorporam-no como parte integrante, sem anular as particularidades de cada um. Acontece onde a diversidade e a proximidade são fontes de integração e cooperação e, ao mesmo tempo, de tensões e conflitos, configurando uma rede de relações recíprocas e complexas. A autora conclui afirmando que se a vida local é o resultado do encontro entre o rural e o urbano, o desenvolvimento local, entendido como o processo de valorização do potencial econômico, social e cultural dessa sociedade, não pode supor o fim do rural (WANDERLEY, 2001).

Essas novas perspectivas sobre o mundo rural se apoiam em argumentos que abrem a possibilidade de o território rural oferecer alternativas de emprego e renda. Mas, para oferecer isso, o território rural tem que utilizar o seu potencial local e aproveitar as suas características históricas e culturais particulares e, também, estar integrado socioeconomicamente com o seu entorno e com o exterior. Estes são os contornos que poderão levar a uma nova ruralidade e contribuir para o desenvolvimento local dos territórios rurais.

\section{Os SIALs como mecanismo de inserção da agricultura familiar no desenvolvimento dos territórios rurais}

Van der Ploeg e Van Dijk (1995) afirmam que a reestruturação geral da economia europeia, no início da década de 1990, atingiu também o desenvolvimento rural, provocando mudanças significativas nos níveis de interação 
entre a sociedade e as empresas. Segundo eles, ainda que a agricultura respondesse bem a essa reestruturação, era necessário dar mais atenção ao tema das sinergias, porque, em muitas experiências de desenvolvimento rural que criaram integração entre as atividades, elas apareceram como cruciais e estratégicas. Entre as sinergias que fortalecem a economia rural, são importantes aquelas entre o território (local) e os ecossistemas regionais e as atividades rurais, tanto quanto as sinergias na produção de bens e serviços específicos e nas cadeias e sistemas agroalimentares locais.

Os sistemas produtivos agroalimentares dos territórios rurais do sul do Brasil, onde a estrutura agrária é caracterizada pela agricultura familiar, vêm caminhando para uma crescente integração socioeconômica desde o final da década de 1960, principalmente do seu segmento de produção agrícola. Essa integração tem sido ocasionada pela reestruturação do sistema produtivo global, pela modernização tecnológica dos processos produtivos agrícolas e pelo crescente acesso das famílias rurais locais aos diversos mercados (de trabalho, de bens e serviços e de fatores). Com isso, afirma Schneider (1999), essas famílias vêm se tornando mais dependentes do mercado e, em consequência, reduzindo a sua autonomia e aumentando a subordinação de suas estratégias de reprodução socioeconômica.

As principais particularidades dos SIALs são: o papel específico dos bens alimentares, pois são os únicos que são literalmente incorporados pelos consumidores no ato de consumo, em vez de serem somente utilizados como muitos outros bens de consumo; a especificidade da matéria-prima produzida, pois a atividade agroalimentar tem origem numa matéria-prima agrícola, viva, heterogênea, sazonal e perecível; a relação com o meio e a gestão dos recursos naturais; e, por fim, as atividades produtivas agroalimentares, ambientais e turísticas, mais do que outras atividades produtivas, estão vinculadas, frequentemente, com uma parte significativa do "saber-fazer" local e com os conhecimentos transmitidos por aprendizagem (SAUTIER, 2002; MUCHINIK, 2002).

Como a definição dos SIAL destaca o local e o papel dos atores dentro do sistema, na forma de organização e no processo de desenvolvimento, a área ocupada pelas unidades de produção agrícola e de serviços ambientais e turísticos deve estar incluída no território representado pelo SIAL. No entanto, a distância entre as empresas, a densidade por unidade de superfície e o grau de concentração variam conforme o tipo de indústria, a natureza da matéria-prima e o processo de evolução do território.

Porém, é muito comum em territórios brasileiros, em regiões do interior, onde predominam cidades pequenas e médias, a presença de alguns tipos específicos de aglomerações produtivas com atividades diversificadas. Elas são formadas por atividades produtivas de bens e serviços agroalimentares, agroindustriais, ambientais e turísticos e, ao mesmo tempo, por outras atividades industriais e de serviços, direta ou indiretamente ligados às primeiras.

\subsection{Os Sistemas Agroalimentares Localizados (SIALs) e a Agricultura Familiar}

Quando a confiança e a fidelidade estão presentes em uma aglomeração produtiva, as relações informais entre as empresas e os agricultores familiares 
crescem, levando esses atores a operarem como se fosse uma unidade econômica com administração descentralizada. Não se descarta a possibilidade de que essas relações de poder possam ser fortemente assimétricas em favor das empresas, caso esses agricultores familiares não estejam organizados em associações ou cooperativas. Assim, abrem-se espaços para parcerias entre as empresas e as organizações desses agricultores por meio de associações e consórcios, já que a proximidade física entre atores e agentes facilita a formação de laços de confiança e cooperação.

O conceito de SIAL tem como seus dois principais pilares os estudos das cadeias ou sistemas agroindustriais ligados à agricultura familiar e a abordagem das aglomerações produtivas (SAUTIER, 2002). Esse autor também destaca a importância das interações entre cadeias agroindustriais e territórios, afirmando que as lógicas das cadeias agroindustriais e as lógicas territoriais são inseparáveis.

Um SIAL pode englobar uma cadeia produtiva estruturada localmente ou concentrar-se em um ou em alguns segmentos de uma cadeia produtiva específica de abrangência nacional ou internacional. Entre os atores participantes dos SIALs, incluem-se os agricultores familiares, as empresas fornecedoras de insumos, as prestadoras de serviços, as associações de classe, as associações comerciais, as instituições de suporte, de serviços, de ensino e pesquisa, de fomento, financeiras e o Estado.

A seguir, apresenta-se alguns resultados de estudos mais quantitativos realizados, entre 2013 e 2015 em dois territórios do Rio Grande do Sul, a região Vale do Caí e parte da região Vale do Taquarí, onde está localizado o território de abrangência da cooperativa Languiru, com sede no Município de Teutônia.

\subsection{A Região Vale do Caí}

O estudo sobre a região Vale do Caí buscou subsídios para a elaboração de uma política de desenvolvimento regional-rural com base nas oportunidades externas, nas potencialidades territoriais-locais e nas diferentes dinâmicas. Por isso, a pesquisa procurou identificar as oportunidades de mercado e as potencialidades locais de atividades produtivas agroalimentares, assim como, o potencial de desenvolvimento de um SIAL na região. Mais especificamente, o estudo buscou analisar o potencial das principais atividades produtivas agroalimentares $\mathrm{e}$ agroindustriais da região Vale do Caí como dinamizadoras do desenvolvimento socioeconômico local, por meio de informações básicas sobre a estrutura de produção. Foi realizado um diagnóstico das principais atividades produtivas agroalimentares e agroindustriais e da relevância econômica dessas atividades para cada um dos municípios da região.

Os indicadores econômicos (PIB agropecuário, valor da produção agrícola, emprego, etc.) e, principalmente, os dados relacionados com a produção e processamento de produtos agroalimentares foram importantes na identificação das potencialidades locais-regionais, fazendo um mapeamento das condições produtivas reais da região, visando à aplicação de políticas adequadas ao desenvolvimento regional. Os dados secundários foram obtidos, basicamente, no IBGE (Censo Agropecuário de 2006 e produção agropecuária municipal), Fundação de Economia e Estatística (FEE), Ministério do Trabalho e Emprego TEM (CAGED, 2012), Empresa de Assistência Técnica e Extensão Rural - Emater, 
Empresa Brasileira de Pesquisa Agropecuária - Embrapa e algumas prefeituras municipais da região.

A região foi colonizada predominantemente por brasileiros de origem lusa a partir de 1740 e por imigrantes alemães desde 1827. A pesquisa abrange os 19 municípios que fazem parte da região administrativa do Corede do Vale do Caí, com uma área de $1.854 \mathrm{~km}^{2}$ e contempla os municípios de: Alto Feliz, Barão, Bom Princípio, Brochier, Capela de Santana, Feliz, Harmonia, Linha Nova, Maratá, Montenegro, Pareci Novo, Salvador do Sul, São José do Hortêncio, São José do Sul, São Pedro da Serra, São Sebastião do Caí, São Vendelino, Tupandi e Vale Real.

Em nível estadual, a região se destaca na produção de tangerina (bergamota), tendo aproximadamente 8 mil hectares cultivados já em 2003. Os principais municípios produtores são Montenegro, Pareci Novo, Harmonia, São José do Sul e São Sebastião do Caí (IBGE, 2009). Quanto à produção de laranja, a região tem mais de 4 mil hectares de pomares comerciais, sendo os principais municípios produtores São Sebastião do Caí, Harmonia, Tupandi, Pareci Novo e Montenegro (IBGE, 2006). A citricultura corresponde a quase $60 \%$ da produção agrícola da região, que concentra também $30 \%$ do processamento de carnes de aves e de suínos do Rio Grande do Sul (IBGE, 2009).

A área média dos estabelecimentos rurais da região é de 11,8 ha, destacando-se principalmente pelo alto percentual (\%) da área média dos estabelecimentos ocupada com: pastagens naturais (potreiros), como em Capela de Santana (14,0 ha); lavouras permanentes (frutas basicamente), como em São Pedro da Serra (8,9 ha) e Pareci Novo (5,2 ha); reflorestamento (florestas plantadas) de Brochier (5,6 ha), Montenegro (5,9 ha), Salvador do Sul (5,6 ha) e Maratá (5,0 ha). Todas essas áreas ocupadas correspondem a mais de $30 \%$ da área total dos estabelecimentos rurais desses municípios.

Montenegro e Capela de Santana, em função das suas características morfológicas, predominando as áreas de campos e planícies, são os grandes produtores de bovinos na região. Merece destaque também a produção de frangos e galinhas nos municípios de Salvador do Sul, Montenegro e Bom Princípio, todos com mais de 1 milhão de cabeças. A produção de suínos é alta nos municípios de Tupandi (47,9 mil cabeças), Montenegro (36,2 mil cabeças) e Maratá (33,4 mil cabeças). A produção animal na região, principalmente a de aves, suínos e ovos de galinha, e o segmento agroindustrial de processamento de derivados de carne bovina, suína e de aves têm grande potencial de crescimento na região.

Quase metade ( $R \$ 47$ milhões) do valor total da produção animal da região ( $R$ \$ 101,2 milhões) teve origem na produção de ovos de galinha ( $R$ \$ 45 milhões), com grande destaque no Município de Salvador do Sul. Além deste, também Alto Feliz e Montenegro têm como significativa fonte de renda a produção de ovos. Essa atividade representa mais de $80 \%$ do total da produção pecuária e aproximadamente $20 \%$ de toda a produção agropecuária da região, com um grau de concentração e dependência em relação a este produto maior em Salvador do Sul e Alto Feliz.

O valor total da produção agroalimentar e agroindustrial (agropecuária) da região foi de quase $R \$ 400$ milhões em 2011. Um terço desse montante foi gerado nos municípios de Montenegro, com 18,4\% do total, $47 \%$ deste sendo originado na produção de tangerina, e de Salvador do Sul, com quase 15\% do total, sendo que $76 \%$ deste tive origem na produção de ovos de galinha. 
Para a região Vale do Caí, a produção leiteira mostra-se como uma alternativa muito consistente, pois pode representar um caminho para a geração de oportunidades de trabalho e renda para os agricultores familiares locais. Para agregar valor ao leite in natura produzido, é necessário que haja investimentos tanto na produção primária de leite resfriado como na de derivados - como queijo, iogurte e demais produtos lácteos - para que seja possível ampliar o horizonte de produção. Com a produção de leite, abre-se a possibilidade de investimentos também na produção e comercialização de rações e outros insumos para os rebanhos. Além disso, a geração de muitos postos de trabalho, indiretamente, poderá beneficiar grande parte da população e do comércio da região, pois a cadeia do leite tem grande potencial para a geração de empregos e para a multiplicação de investimentos locais.

A distância média entre os municípios mais centrais da região Vale do Caí e a capital Porto Alegre é de aproximadamente $60 \mathrm{~km}$. Na região metropolitana de Porto Alegre - RMPA vivem em torno de 4 milhões de habitantes (35\% desta em Porto Alegre), quase $43 \%$ da população urbana do Rio Grande do Sul, com uma densidade demográfica de mais de 405 hab. $/ \mathrm{km}^{2}$ e uma taxa de urbanização de mais de $96 \%$ (FEE, 2012). Sem dúvida, a RMPA é um dos mais importantes mercados brasileiros para produtos agroalimentares e agroindustriais.

O conjunto das principais atividades ou segmentos de algumas cadeias produtivas agroalimentares presentes, ou com potencial de expansão, na região Vale do Caí, por serem grandes geradoras de oportunidades de trabalho e de renda, podem ser o embrião para a formação de um SIAL na região. Portanto, por serem importantes na dinâmica socioeconômica de desenvolvimento regional, poderão potencializar o desenvolvimento sustentável da região Vale do Caí, principalmente pelo fato de os estabelecimentos rurais da região terem uma área média que não chega a 12 ha, com mão de obra predominantemente familiar.

Ficou como sugestão também que para se ter uma ideia exata do potencial de formação de um SIAL e das estratégias de desenvolvimento das atividades agroalimentares na região Vale do Caí, será necessário ainda, num segundo momento, realizar um estudo com caráter mais qualitativo. Este seria realizado em cada um dos segmentos das cadeias presentes hoje na região, incluindo as estratégias dos agricultores familiares, cooperativas, agroindústrias e demais empresas locais do setor agroalimentar regional.

\subsection{A Região de Abrangência da Cooperativa Languiru}

A articulação da agricultura familiar com uma determinada agroindústria cooperativa acontece por meio de um conjunto de relações sociais, de trabalho e de produção, que passam a ser integrantes de um complexo e diversificado sistema de relações, constituindo uma aglomeração produtiva local (Schneider, 1999). Essas relações possuem uma historicidade e uma especificidade que diferenciam esses sistemas produtivos locais, tanto em relação ao exterior como entre eles.

Nos SIALs, há uma relação muito próxima entre os modos de produção dos bens e serviços, as preferências dos consumidores e a economia rural centrada na transformação e na comercialização de bens e serviços vindos, predominantemente, de unidades rurais familiares de pequena escala. Esses 
sistemas são resultantes das formas regionais de organização da produção e da reprodução social pela vinculação de uma atividade produtiva principal com atividades conexas e complementares, onde se incluem aquelas realizadas pela agricultura familiar, e destas, com uma determinada rede urbana.

A população da região de abrangência da Cooperativa, estimada para 2015 ainda não ultrapassa 100 mil habitantes, sendo 87\% concentrada em Teutônia e Estrela. Verifica-se também que a área média dos estabelecimentos rurais nesses sete municípios que formam o território de abrangência da Cooperativa é de 11,6 ha, sendo este, ao lado da predominância do trabalho familiar, um dos mais importantes indicativos para caracterizar os estabelecimentos rurais do território como de agricultura familiar. Os municípios considerados na região de abrangência foram os de Arroio do Meio, Colinas, Estrela, Imigrante, Poço das Antas, Teutônia e Westfália.

Como justificativa da importância da Cooperativa na geração de empregos, cabe destacar que somente o frigorífico de aves em Westfália é responsável por $66 \%$ do total de empregos formais do município e o frigorifico de suínos em Poço das Antas emprega mais de $71 \%$ da população com emprego formal no município

Entre os municípios representativos do território de abrangência da cooperativa, os dois principais produtores e fornecedores de aves para a mesma são Teutônia e Westfália, respectivamente, 23,3\% e 39,2\% do que a Languiru recebe. Esses dois municípios fornecem mais de 15,6 milhões dos 37,2 milhões de frangos que a Cooperativa recebe por ano, provavelmente por estar localizado neste último o frigorífico de aves da cooperativa. A cooperativa recebe mais $90 \%$ da produção total de aves de Teutônia $(94,1 \%)$ e Westfália $(91,0 \%$ ) e de $80,2 \%$ da de Colinas.

A produção total de suínos dos municípios que compõem o território de abrangência da Cooperativa foi estimada, com base nos dados do IBGE (2015), em 937.146 cabeças, em 2014 , sendo que $29,4 \%$ dessa quantidade foi recebida pela Languiru. Os maiores produtores foram os municípios de Arroio do Meio (214.760), Estrela (211.820) e Teutônia (195.314). Embora o Município de Poço das Antas seja a sede do frigorífico de suínos, ele fornece uma quantidade bastante baixa de suínos para o abate.

A produção total de leite nos sete municípios que formam a região de abrangência da Languiru é de quase 137 milhões de litros, mas apenas 57,3 \% desse volume são destinados à cooperativa, o que pode demonstrar que ainda há potencial para expansão do número de fornecedores dessa matéria-prima na região. Em 2014, a produção leiteira de mais de 120 milhões de litros recebida pela Cooperativa foi produzida de forma pulverizada, com apenas 57,4\% desse volume sendo produzido nos sete municípios que formam o território de abrangência da Cooperativa. Dentre os municípios que fazem parte da região de abrangência, Teutônia $(20,1 \%)$, Estrela $(16,0 \%)$ e Westfália $(9,7 \%)$ são os principais fornecedores de leite para a cooperativa. Dois municípios, que também são grandes produtores de leite na região e que têm um alto percentual de sua produção destinada à cooperativa, são Westfália e Teutônia, respectivamente, com $84 \%$ e 75,4 \%. Em Teutônia, onde houve um crescimento de $74 \%$ na produção de leite entre 2005 e 2014, está localizada a agroindústria de laticínios da Languiru. 
As estimativas do valor agregado na produção de carnes de aves e suínos, laticínios e embutidos foram realizadas por meio do cálculo da diferença entre o que é pago ao associado pela cooperativa, como sendo o custo total da matériaprima, baseado na produção recebida dos associados pela cooperativa, a partir dos dados fornecidos pela cooperativa no relatório de atividades de 2014 , e os valores relativos à participação de cada um dos segmentos produtivos na formação do faturamento bruto da cooperativa em 2014. Verifica-se, na tabela 1, que a agregação de valor relativa sobre o faturamento bruto foi de $35,5 \%$. Para o segmento de embutidos, foi considerado que eles foram processados a partir dos mesmos animais (aves e suínos) que foram recebidos pela cooperativa para a produção de carnes. Por isso, se for considerado que a maior parte dos embutidos tem a carne suína como matéria-prima básica, seria aceitável que grande parte do valor agregado ( $\mathrm{R} \$ 71.659 .645)$ pelo segmento dos embutidos poderia ser direcionado ao segmento de suínos.

Tabela 1. Valor agregado pela agroindustrialização (2014) - em $R \$$

\begin{tabular}{ccccc}
\hline & Pago ao associado & Faturamento bruto & Agregado (R\$) & Agregado (\%) \\
\hline Aves & $210.183 .341,0$ & 295.960 .160 & $85.776 .818,7$ & 29,0 \\
Suínos & $110.057 .755,0$ & 133.415 .111 & $23.357 .356,4$ & 17,5 \\
Leite & $156.932 .679,0$ & 238.477 .084 & $81.544 .405,0$ & 34,2 \\
Embutidos & - & 71.659 .645 & $71.659 .645,0$ & 100,0 \\
\hline Total & 477.173 .775 & 739.512 .000 & 262.338 .225 & 35,5 \\
\hline
\end{tabular}

Fonte: Elaborado pelo autor com base nos dados do Relatório de Atividades 2014 (n.p.).

A articulação e/ou integração das cadeias produtivas agroalimentares e agroindustriais com outros setores, e do rural com o urbano, tem sido o caminho seguido por alguns territórios rurais. Esse é o caso do território formado pelos sete municípios que mantêm maiores vínculos com as atividades da Cooperativa Languiru, com uma significativa presença de agricultores familiares. Essa seria uma resposta local às mudanças provocadas pela reestruturação do sistema produtivo global, ao modelo atual de modernização tecnológica dos processos produtivos agroindustriais e ao crescente acesso das famílias rurais aos diversos mercados locais (de trabalho, de bens e serviços e de fatores).

Muitos territórios rurais ainda se sustentam economicamente por meio de atividades de produção agropecuárias, ao lado de atividades agroindustriais, exercidas por pequenas e médias empresas, capitalistas ou cooperativas. Enfim, o desenvolvimento desses territórios depende das dinâmicas externas, como mercados agroalimentares ou agroindustriais, e das dinâmicas internas.

\section{Considerações finais}

A construção de um sistema local autônomo e mais integrado às redes globais deve ser parte de uma estratégia de desenvolvimento que coloca o poder público, associações, cooperativas, movimentos sociais e os demais agentes econômicos como atores fundamentais do desenvolvimento. Assim, espera-se que seja possível a promoção do desenvolvimento socioeconômico dos territórios rurais por meio do atendimento das necessidades sociais, da ampliação da democracia local nas decisões econômicas e do incremento ou expansão de atividades 
produtivas locais, mais rentáveis e geradoras de postos de trabalho. Entre estas, aparecem com grande potencial de contribuição para alavancar e promover o desenvolvimento socioeconômico de uma região as atividades de produção e distribuição de bens e serviços agroalimentares, ambientais e turísticos, potencialmente geradoras diretas de renda e ocupações, como multiplicadoras desses benefícios para outras atividades locais, industriais ou de serviços.

Um novo modelo de desenvolvimento com capacidade para impulsionar o desenvolvimento humano e elevar a qualidade de vida das populações rurais tem que levar em conta a realidade e a diversidade dos territórios ou regiões. Assim, seria possível formular políticas e instrumentos de fomento produtivo e de modernização tecnológica mais ajustados ao perfil específico de cada território e às potencialidades locais. Como a abordagem teórica do desenvolvimento territorial se detém mais nas questões locais ou regionais, ela apresenta muitas contribuições para a problemática das desigualdades regionais e instrumentos de políticas para a correção dessas desigualdades.

Autores que abordam o tema do desenvolvimento rural sugerem a possibilidade de os SIALs, um tipo específico de aglomeração produtiva, tornarem-se um importante mecanismo de articulação da agricultura familiar com os mercados consumidores de alimentos e de serviços ambientais e turísticos, com a dinâmica de desenvolvimento dos territórios rurais e com o processo de reestruturação do sistema produtivo global. Admite-se também a hipótese de que a intervenção no SIAL possa ser uma estratégia para melhorar o desempenho da ação pública. Porém, uma mesma estratégia de intervenção, executada em diferentes contextos, pode produzir desempenhos muitos diferentes e inesperados.

Deve ser destacado o papel dos atores sociais e das instituições nas dinâmicas de desenvolvimento dos territórios rurais, que estão associadas as suas diferentes possibilidades de intervenção, procurando-se enfatizar a importância da organização, cooperação, reciprocidade e participação do Estado, atores e demais instituições locais. No entanto, é necessário verificar até que ponto a diversificação de setores, a integração territorial e as transformações nas aglomerações produtivas e nas estruturas socioeconômicas regionais podem ser entendidas como decorrentes de ações sociais locais e de mudanças na gestão local do território e dos recursos endógenos.

Os resultados de um estudo das alternativas produtivas da região Vale do Caí mostraram que é de grande relevância a possibilidade de que as mesmas possam contribuir para a eficácia de medidas e políticas de desenvolvimento regional-rural. Essas alternativas poderiam aproveitar o potencial endógeno do território, a capacidade produtiva da agricultura familiar da região e as oportunidades de mercado oferecidas, principalmente, pelo alto potencial de consumo da população da região Metropolitana de Porto Alegre. Além do fato de poderem se adaptar muito bem à agricultura familiar da região espera-se também que as atividades agroalimentares sejam dinamizadoras e transformadoras da realidade socioeconômica em escala regional e tenham substancial efeito multiplicador na geração de renda e de ocupações para a população desse território.

O que se verifica quando se estuda os territórios rurais mais dinâmicos é que há um ambiente onde são utilizadas algumas potencialidades próprias do território e são aproveitadas as oportunidades externas. Nesses territórios, há uma dinâmica 
socioeconômica local diferenciada de desenvolvimento regional-rural instrumentalizada e mediada por meio de cadeias produtivas, que, no caso do território de abrangência da Cooperativa Languiru, são as de carnes de aves e de suínos e a de lácteos.

$\mathrm{Na}$ dinâmica desse território, as potencialidades locais se verificam na presença da agricultura familiar e do capital social (representado, principalmente, pela confiança e a reciprocidade entre associados e cooperativa) e da disponibilidade de terras férteis, infraestrutura de transporte (estradas asfaltadas) e logística, entre outros. Enquanto que as oportunidades externas são representadas pela disponibilidade tecnológica e a proximidade com mercados consumidores de alimentos, com poder aquisitivo relativamente elevado como é o da região Metropolitana de Porto Alegre. Além dessas, também há a possibilidade de acesso aos grandes mercados consumidores externos de alimentos processados, principalmente de frangos e derivados, como a China, países árabes do Oriente Médio e de outros países asiáticos.

Assim, as ligações e as relações entre o local e o global dentro de territórios rurais com predominância de agricultores familiares podem ser realizadas pelas cooperativas agroalimentares ou agroindustriais. Nas duas situações descritas acima, tanto no caso da Cooperativa Languiru como no caso da região Vale do Caí, verifica-se uma articulação da agricultura familiar com a dinâmica de desenvolvimento desses territórios rurais e com o processo de reestruturação do sistema produtivo global. Mas essa articulação parece acontecer de uma forma que se aproxima muito com a teoria dos nichos de mercado de Friedland, sintetizada na seção 2 deste artigo, que rejeita as teses do fim do fordismo e tem a forma de uma transição para o pós-fordismo.

Por fim, os efeitos do processo de reestruturação produtiva capitalista sobre a agricultura e os territórios rurais, ao contrário de produzir um esvaziamento demográfico pela intensificação do êxodo rural, como vem acontecendo desde o início da modernização da agricultura brasileira, poderá abrir novas oportunidades e desacelerar, ou até interromper, o fluxo migratório. A busca por melhor qualidade de vida, expansão da infraestrutura rural, diversificação de atividades agroalimentares, agroindustriais e turísticas que utilizem os recursos ambientais de forma sustentável e gerem renda e emprego para as famílias rurais são fatores que podem contribuir para uma reversão dos fluxos migratórios.

\section{REFERÊNCIAS}

ABRAMOVAY, Ricardo. Funçôes e medidas da ruralidade no desenvolvimento contemporâneo. Texto para Discussão n 702 - IPEA - Rio de Janeiro: 2000.

BECKER, Bertha. O Uso Político do Território: questões a partir de uma visão do terceiro mundo. In: BECKER, Bertha; COSTA, Rogério; SILVEIRA, Carmem (orgs.). Abordagens Políticas da Espacialidade. Rio de Janeiro: UFRJ, p.1-8, 1986.

BECKER, Bertha. Modernidade e Gestão do Território no Brasil: da integração nacional à integração competitiva. In: Espaço e Debates, São Paulo, n. 31, p. 47$56,1991$. 
BENKO, G.. Economia, Espaço e Globalização: na aurora do século XXI. São Paulo: Hucitec-Annablume, 2002.

BOISIER, Sergio E.. Sociedad civil, participacion, conocimiento y gestion territorial. Santiago de Chile, ILPES: 1997.

BONANNO, A.. A Globalização da economia e da Sociedade: fordismo e pósfordismo no setor agroalimentar, 1998.

BONANO, A.;T. MARSDEN \& J. GRAZIANO DA SILVA. Globalização $e$ Localização: elementos para entender a reestruturação dos espaços rurais. In: Cavalcanti, S. (org), Globalização, Trabalho e Meio Ambiente. Recife, Editora UFPE, p.341-366, 1999.

BONANNO, A et al.. From Columbus to Conagra: the globalisation of food and agriculture. University of Kansas Press, Lawrence, KS, 1994.

BOYER, R. Secteurs, Régions et Modes de Régulation. In: La Grande Transformation de L'Agriculture, G. Allaire e R. Boyer (ed.). INRA e Economica, 1995.

CAVALCANTI, J. S. B., org. Globalização, trabalho, meio ambiente: mudanças socioeconômicas em regiões frutícolas para exportação. Recife: Editora Universitária da UFPE, 1999.

FRIEDLAND, W. The new globalisation: the case of fresh produce. In Bonanno, A et al (eds) From Columbus to Conagra. University of Kansas Press, 1994.

GRAZIANO DA SILVA, J. A Globalização Da Agricultura. In: Silveira, M.A. Da; Vilela, S.L. de O., ed. Globalização e Sustentabilidade da agricultura. Jaguariúna: Embrapa Meio Ambiente, 1998. p.29-42. (Embrapa Meio Ambiente. Documentos, 15)

LACROIX A. e MOLLARD, A . L'Approche Sectorielle de La Régulation: une problématique à partir de l'agriculture. In: La Grande Transformation de L'Agriculture, G. Allaire e R. Boyer (ed.). INRA e Económica, 1995.

MARSDEN, T. K. New Rural Territories: regulating the differentiated rural spaces. Journal of Rural Studies, v.14, n.1, p.107-117, 1998.

MARSDEN, T.K. Creating space for food: the distinctiveness of recent agrarian development. In_Goodman. D and Watts.M (eds) Globalising Food: agrarian questions and global restructuring. Routledge, London: 1997.

SACK, Robert. Humam Territoriality. Theory and History. Cambridge: Cambridge University Press, 1980.

SCHNEIDER, S. Agricultura familiar $e$ industrialização: pluriatividade $e$ descentralização industrial no Rio Grande do Sul. Porto Alegre, Ed. UFRGS, 1999. 
SCHNEIDER, S.. A Pluriatividade na Agricultura Familiar. Porto Alegre, Ed. da UFRGS, 2003.

Submetido em 29/05/2016

Aprovado em 12/07/2016

\section{Sobre o Autor}

Jorge Luiz Amaral de Moraes

Agrônomo, Mestre em Economia Rural (UFRGS) e Doutor em Desenvolvimento Rural (UFRGS).

Professor do Departamento de Ciências Econômicas da Universidade de Santa Cruz do Sul (UNISC)

e do Programa de Pós-Graduação em Desenvolvimento Regional das Faculdades Integradas de Taquara (FACCAT).

E-mail: jmoraes12@gmail.com. 